\title{
Perinatal Hypoxia/lschemia Damages and Depletes Progenitors from the Mouse Subventricular Zone
}

\author{
Christine Y. Brazela Robert T. Rosti III ${ }^{b}$ Sheri Boyce ${ }^{c}$ Raymond P. Rothstein ${ }^{d}$ \\ Steven W. Levison ${ }^{b}$ d
}

a Stem Cell Biology Unit, Laboratory of Neurosciences, National Institute on Aging, Gerontology Research Center, Baltimore, Md., b Department of Neural and Behavioral Sciences, Pennsylvania State University College of Medicine, Hershey, Pa., 'Department of Biology, Messiah College, Grantham, Pa., and dDepartment of Neurology and Neuroscience, UMDNJ-New Jersey Medical School, Newark, N.J., USA

\section{Key Words}

Caspase 3 - Apoptosis · Stem cells · Neonate brain injury, asphyxia

\begin{abstract}
Hypoxia-ischemia $(\mathrm{H} / \mathrm{l})$ as a result of asphyxia at term remains a major cause of neurologic disability. Our previous studies in the $\mathrm{P} 7$ rat model of perinatal $\mathrm{H} / \mathrm{I}$ have shown that progenitors within the subventricular zone (SVZ) are vulnerable to this insult. Since many investigators are using transgenic and knockout mice to determine the importance of specific molecules in the evolution of damage after a stroke, there is a need to perform comparative studies on the relative vulnerability of the mouse SVZ. Here we assess damage to the SVZ of 5-, 7- and 10day-old C57BL/6 mice after unilateral common carotid artery cauterization followed by $70 \mathrm{~min}$ of $\mathrm{H} / \mathrm{l}\left(10 \% \mathrm{O}_{2}\right)$. Whereas 5- and 7-day-old mice sustained little SVZ damage as assessed by hematoxylin and eosin staining, there was a $16 \%$ reduction of cellularity in 10 -day-old animals by $18 \mathrm{~h}$ of recovery. Additionally, swollen cells were observed in the medial region of the SVZ of 10-day-old mice. However, few caspase-3+ and TUNEL+ cells were observed in this region, which contains the putative neural stem cells. Rather, the majority of the dying cells were situated in the mediolateral and lateral tail of the SVZ. At $18 \mathrm{~h}$ of recovery, there was a 2 -fold increase in the frequen-
\end{abstract}

\begin{tabular}{ll}
\hline KARGER & (c) 2004 S. Karger AG, Basel \\
$\begin{array}{l}\text { Fax + 41 61 306 1234 } \\
\text { E-Mail karger@karger.ch } \\
\text { www.karger.com }\end{array}$ & $\begin{array}{l}\text { Accessible online at: } \\
\text { www.karger.com/dne }\end{array}$
\end{tabular}

cy of TUNEL+ cells in the ipsilateral SVZ as well as a 3-fold increase in the frequency of active-caspase-3+ cells. We conclude that progenitors within the neonatal mouse SVZ are vulnerable to hypoxic/ischemic insult. The demise of these early progenitors likely leads to depletion of neuronal and late oligodendrocyte progenitors, contributing to cerebral dysgenesis.

Copyright $@ 2004$ S. Karger AG, Basel

\section{Introduction}

Brain injury due to hypoxia-ischemia (H/I) as a result of intrapartum birth asphyxia remains a major cause of neurologic disability. The brain damage that can occur has been associated with a number of disorders, including cerebral palsy and epilepsy, as well as cognitive and motor deficits. Adjacent to the white matter and the basal ganglia structures that frequently sustain damage following $\mathrm{H} / \mathrm{I}-$ is a highly cellular structure referred to as the germinal matrix. This region harbors neural stem cells, transient amplifying progenitor cells and a variety of lineagerestricted precursors that are essential seeds for the new cells that the developing brain requires. The rodent equivalent of the germinal matrix is the subventricular zone (SVZ). Brain damage to the cerebral hemispheres following perinatal H/I in the postnatal day 7 (P7) rat has been extensively characterized [reviewed in 1], and in recent years the

Steven W. Levison, PhD

Department of Neurology and Neuroscience, UMDNJ-New Jersey Medical School

185 South Orange Avenue, H-506

Newark, NJ 07103-170 (USA)

Tel. +1973676 1000, ext. 1155, Fax +1973 395 7233, E-Mail levisosw@umdnj.edu 
Rice-Vannucci model of perinatal $\mathrm{H} / \mathrm{I}$ has been adapted for use in P10 mice [2-6]. Contributing to the literature on developmental brain damage, we have characterized and reported the impact of this insult on the cells of the SVZ. Our studies have shown that subsequent to this insult, a large number of cells die in both the mediolateral and the lateral aspects of the P7 rat SVZ and that caspase 3 activation mediates the death of a subpopulation of these cells [7-9]. Since many investigators are using transgenic and knockout mice to determine the importance of specific molecules in the evolution of damage after $\mathrm{H} / \mathrm{I}$, there is a need to characterize the vulnerability of the cells in the mouse SVZ; however, detailed histopathologic studies have not yet been performed to date. Here we assess the damage to the SVZ of P5, P7 and P10 mice after an H/I insult to determine whether SVZ cells in the mouse are vulnerable to this insult and whether there are age-related differences in the extent of cell death.

\section{Materials and Methods}

\section{Animals}

Experimental animals were housed and cared for by the Department of Comparative Medicine at the Hershey Medical Center, which is a facility accredited by the Association for Assessment and Accreditation of Laboratory Animal Care. Animal experimentation was conducted in accordance with the Society for Neuroscience's Policy on the Use of Animals in Neuroscience Research.

\section{Perinatal $\mathrm{H} / \mathrm{I}$}

C57BL/6 mice were purchased from Jackson Laboratories (Bar Harbor, Me., USA) and were group housed prior to pregnancy, whereupon the dams were individually housed. Mouse pups were delivered vaginally; the day of birth was designated P1. Cerebral H/I was produced in 5- (1.8-2.0 g), 7- (2.6-3.1 g) and 10-day-old mice (4.5-5.0 g) by a permanent unilateral common carotid cauterization followed by systemic hypoxia. Briefly, male and female pups were lightly anesthetized with isoflurane (4\% induction, $2.5 \%$ maintenance). Once fully anesthetized, a midline neck incision was made, and the right common carotid artery was identified. The common carotid artery was separated from the vagus nerve and then cauterized using a bipolar cauterizer at a power setting of 10 . Animals were returned to the dam for $2 \mathrm{~h}$. Sham-operated animals underwent the same surgical treatment without the cauterization. Before exposure to hypoxia $\left(10 \% \mathrm{O}_{2} / 90 \% \mathrm{~N}_{2}\right)$, the pups were prewarmed in jars for 20 min submerged in a $37^{\circ} \mathrm{C}$ water bath. The pups were then exposed to $70 \mathrm{~min}$ of hypoxia. After hypoxia, the pups were allowed to recover in the jars for $20 \mathrm{~min}$ and were then returned to the dam for recovery periods of $4-48 \mathrm{~h}$, at which point they were sacrificed.

Histology and Terminal Transferase dUTP Nick End Labeling

Animals were sacrificed by decapitation, and the heads were immersion fixed in 3\% paraformaldehyde in $0.1 \mathrm{M}$ phosphate buffer for $6 \mathrm{~h}$ at $4^{\circ} \mathrm{C}$. Brains were removed and fixed in the same fixative overnight at $4^{\circ} \mathrm{C}$. For paraffin sections, the brains were then coronally blocked and processed for paraffin embedding. Six-micrometer coro- nal sections were cut at the level of the anterior commissure and stained with Mayer's hematoxylin and eosin. For cryostat sectioning, the fixed brains were placed in $30 \%$ sucrose overnight at $4{ }^{\circ} \mathrm{C}$ before being blocked and frozen in OCT freezing medium over dry ice and ethanol. Twelve-micrometer coronal sections were cut at the level of the anterior commissure and stained with Mayer's hematoxylin and eosin. Other sections were processed for terminal transferase dUTP nick end labeling (TUNEL). Sections were incubated for $1 \mathrm{~h}$ at room temperature in $300 \mathrm{U} / \mathrm{ml}$ terminal transferase enzyme (TdT) and $10 \mathrm{~m} M$ digoxigenin DNA labeling mixture in TdT buffer and then incubated in TdT stop solution for $10 \mathrm{~min}$ [10]. Sections were rinsed, incubated for $10 \mathrm{~min}$ at room temperature in TGB Superblock and then incubated for $2 \mathrm{~h}$ at $4^{\circ} \mathrm{C}$ in horseradish-peroxidase (HRP)-conjugated sheep antidigoxigenin TGB diluent. Sections were rinsed extensively, and the staining was visualized with Vector Nova Red HRP substrate kit (Burlingame, Calif., USA) and briefly counterstained in Mayer's hematoxylin (20 s), then dehydrated through an ascending alcohol series ending with xylene and coverslipped with cytoseal.

\section{Active Caspase 3 Detection}

Cryostat sections were blocked in TGB diluent, then incubated in antibodies against active caspase 3 (Cell Signaling of New England BioLabs, Beverly, Mass., USA). After extensive washes, the sections were incubated with GAR-HRP, and active caspase 3 was visualized with Nova Red. Sections were briefly counterstained with hematoxylin before dehydrating and coverslipping with cytoseal. Images were captured using a Photometrics cooled charged coupled device camera (Tucson, Ariz., USA) interfaced with IP laboratory scientific imaging software (Scanalytics Fairfax, Va., USA).

\section{Data Collection}

Numbers of TUNEL+ or caspase-3+ cells were determined versus total cell number in the SVZ of H/I animals and sham-operated controls. To analyze the incidence of cell death across the dorsolateral SVZ at the level of the anterior commissure, the SVZ was separated into three distinct regions: medial, mediolateral and lateral. The medial region includes the first two cell layers immediately subjacent to the lateral ventricle (approx. $10 \mu \mathrm{m}$ ). The mediolateral region extends from approximately 10 to $200 \mu \mathrm{m}$ from the lateral ventricle, and the lateral tail extends from $200 \mu \mathrm{m}$ to the most lateral tip of the SVZ. For each region, the percentage of positive cells from the total cells per field was determined at a magnification of $\times 60$ under oil immersion. Additionally, the average cellularity of the SVZ was assessed by determining the number of cells per field. The Abercrombie correction was applied for the analysis of the average cellularity of the SVZ [11]. All values represent the average counts taken from 3 nonadjacent sections per brain from at least 4 animals per time point.

\section{Results}

\section{Seventy Minutes of H/I Reduce the Cellularity of the P10 SVZ at 18 h Recovery}

To determine whether $\mathrm{H} / \mathrm{I}$ reduces the cellularity of the mouse SVZ, we cauterized the right common carotid artery of P5, P7 and P10 mice and subjected them to $70 \mathrm{~min}$ of $10 \% \mathrm{O}_{2}$ in jars submerged in $37^{\circ} \mathrm{C}$ water. At 4 and $48 \mathrm{~h}$ recovery, brains were removed, fixed and paraffin em- 

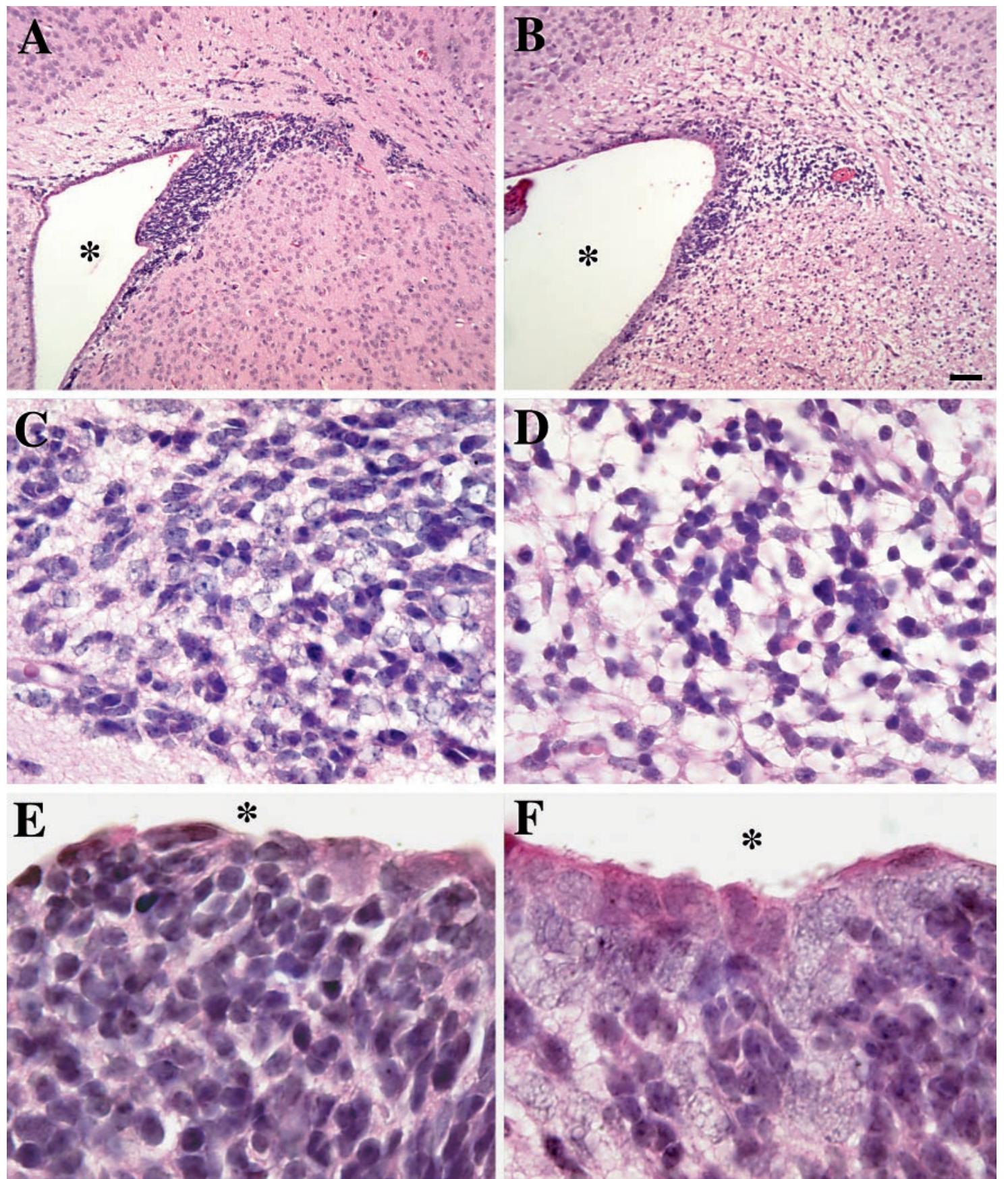

Fig. 1. H/I induces swelling and decreases the cellularity of the P10 mouse SVZ. Asterisks demarcate the lateral ventricle. Six-micrometer-thick paraffin sections taken at the level of the anterior commissure from P10 mice undergoing $70 \mathrm{~min}$ of H/I were stained with Mayer's hematoxylin and eosin. A Representative contralateral SVZ of the P10 mouse taken at $\times 20$ at $48 \mathrm{~h}$ recovery. B Representative ipsilateral SVZ of the P10 mouse taken at $\times 20$ at $48 \mathrm{~h}$ recovery. C Representative mediolateral region of the contralateral SVZ of the P10 mouse taken at $\times 60$ at $48 \mathrm{~h}$ recovery. D Representative mediolateral region of the ipsilateral SVZ of the P10 mouse taken at $\times 60$ at $48 \mathrm{~h}$ recovery. E Representative medial region of the contralateral SVZ of the P10 mouse taken at $\times 60$ at $4 \mathrm{~h}$ recovery. $\mathbf{F}$ Representative medial region of the ipsilateral SVZ of the P10 mouse taken at $\times 60$ at $4 \mathrm{~h}$ recovery. Scale bar $=$ $60 \mu \mathrm{m}$ in $\mathbf{A}$ and $\mathbf{B}, 6 \mu \mathrm{m}$ in $\mathbf{C}-\mathbf{F}$. 
bedded. Other brains were cryoprotected and frozen for cryostat sectioning. Both paraffin and cryostat sections were stained using Mayer's hematoxylin and eosin. The cellularity of each contralateral and ipsilateral SVZ was determined at $18 \mathrm{~h}$ recovery by counting the total number of nuclei present in two nonadjacent sections per animal and applying the Abercrombie correction. Damage to the SVZ in the form of loss of cells and appearance of pyknotic nuclei was rarely seen in the $\mathrm{P} 5$ mouse at $18 \mathrm{~h}$ recovery, suggesting that the P5 mouse SVZ may not be affected using the parameters employed here (data not shown). By contrast, damage was discerned in both the P7 and P10 mouse SVZs; thus, we focused our studies on these two age groups. The average number of cells per SVZ was determined from 4 animals at P7 and for 15 animals at P10. H/I did not produce a loss of cellularity in the ipsilateral SVZ in P7 mice as compared to the contralateral hemisphere at $18 \mathrm{~h}$ recovery $(75.4 \pm 2.65$ vs. $79.9 \pm 4.2$ cells, respectively; $p=0.99)$. However, at $18 \mathrm{~h}$ recovery, the ipsilateral SVZ of the P10 mouse showed a $15.8 \%$ decrease in cellularity when compared to the contralateral SVZ $(65.5 \pm 2.7$ vs. $74.2 \pm 3.5$ cells, respectively; $\mathrm{p}<0.0005)$. By $48 \mathrm{~h}$, the decrease in cellularity is easily seen in the ipsilateral SVZ of the P10 mouse (fig. 1A, B), with the majority of cellular thinning occurring in the mediolateral region of the SVZ (fig. 1C, D). Interestingly, at just $4 \mathrm{~h}$ of recovery, the most medial region of the ipsilateral P10 SVZ is distorted by swelling such that columns of cells are formed (fig. 1E, F). There were no discernable differences between the cellularity of the contralateral hemisphere and sham-operated controls (data not shown).

\section{TUNEL + Cells Are Increased in the SVZ of both P7 and P10 Mice $18 \mathrm{~h}$ following $70 \mathrm{~min}$ of $\mathrm{H} / \mathrm{I}$}

To determine whether the loss of cells from the SVZ is a consequence of an increase in the percentage of apoptotic deaths, we determined the frequency of TUNEL+ cells in the ipsilateral SVZ. TUNEL utilizes terminal transferase to label both single- and double-strand breaks in the DNA and will label cells undergoing apoptosis. An 18-hour recovery was chosen since the peak of apoptosis in the P7 rat SVZ occurs between 12 and $24 \mathrm{~h}$ [9]. Sections were counterstained briefly with hematoxylin to visualize all nuclei in the sections, and the fraction of labeled cells was quantified. TUNEL+ cells were sparse in the contralateral SVZ of P7 mice. By contrast, H/I increased the frequency of TUNELstained cells in the ipsilateral SVZ (fig. 2A, B). Interestingly, there was a nonuniform distribution of the dying cells. In particular, few if any TUNEL+ cells were seen in the first two cell layers immediately subjacent to the lateral ventri- cle in the affected hemisphere, which is the region of the SVZ where the neural stem cells reside. TUNEL+ cells could occasionally be identified in the mediolateral aspect of the contralateral SVZ (fig. 2C). H/I increased the number of TUNEL+ cells in the mediolateral aspect of the ipsilateral SVZ at $18 \mathrm{~h}$ following the insult (fig. 2D). Additionally, TUNEL+ cells were increased in the lateral aspect of the ipsilateral SVZ $18 \mathrm{~h}$ following the insult, as compared to the contralateral hemisphere (fig. 2E, F).

To determine whether the character of the insult changed as the animals developed, cryostat sections from similarly treated P10 mouse pups were processed for TUNEL and counterstained with hematoxylin. Few if any TUNEL+ cells were identified in the contralateral SVZ (fig. 3A) whereas TUNEL+ cells were numerous in the ipsilateral SVZ (fig. 3B). Again, regional differences were observed. Few if any TUNEL+ cells were seen in the first two cell layers immediately subjacent to the lateral ventricle in either the ipsilateral or contralateral hemispheres. Like the P7 mouse SVZ, the mediolateral aspect of the contralateral SVZ contained a few TUNEL+ cells (fig. 3C), and H/I increased the frequency of TUNEL+ cells in the mediolateral aspect of the ipsilateral SVZ (fig. 3D). Similarly, the lateral aspect of the contralateral SVZ contained few TUN$\mathrm{EL}+$ cells (fig. 3E), and $\mathrm{H} / \mathrm{I}$ greatly increased cells positive for TUNEL in the lateral aspect of the ipsilateral SVZ (fig. 3F).

To determine whether H/I reproducibly increased the incidence of TUNEL+ cells in the ipsilateral SVZ, the percentage of TUNEL+ cells was quantified for both the contralateral and the ipsilateral SVZ at $18 \mathrm{~h}$ following the insult (fig. 4). Previous studies in the rat demonstrate no significant differences in the amount of cell death between the contralateral hemisphere and sham-operated controls [9]; thus, we utilized the contralateral hemisphere as the yoked control in these experiments. H/I significantly increased the percentage of TUNEL+ cells in the ipsilateral SVZ as compared to the contralateral SVZ of both P7 (5.4 $\pm 1.0 \mathrm{vs.}$ $1.8 \pm 0.2 \%$, respectively; $p<0.03)$ and $P 10$ mice $(6.0 \pm 0.8$ vs. $2.9 \pm 0.5 \%$, respectively; $p<0.03)$. When we quantified the regional distribution of the TUNEL+ cells in the P10 mouse, a small percentage (less than $0.25 \%$ ) of the cells located in the first two cell layers of the ipsilateral SVZ were positive for TUNEL. By contrast up to $7 \%$ of the cells in the more lateral regions of the SVZ were TUNEL+, and H/I increased this incidence up to $12 \%$ in the mediolateral region (10- $200 \mu \mathrm{m}$ from the ventricular surface) and to $13 \%$ in the lateral SVZ $>200 \mu \mathrm{m}$ from the ventricular surface) of the ipsilateral SVZ as compared to the contralateral hemisphere (fig. 5). 

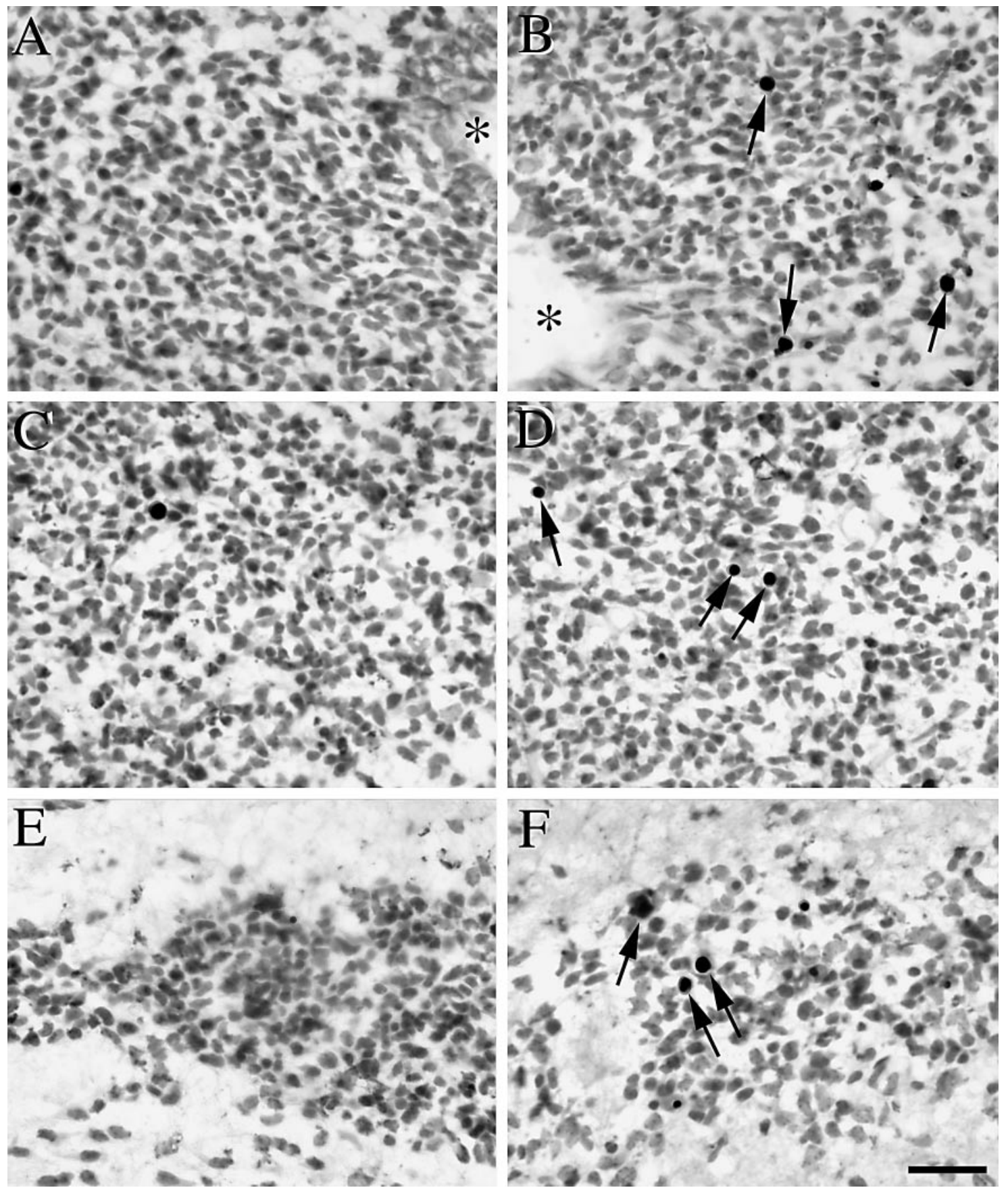

Fig. 2. TUNEL+ cells in the $P 7$ mouse SVZ at $18 \mathrm{~h}$ recovery. Cryostat sections taken at the level of the anterior commissure from $\mathrm{P} 7$ mouse brain at $18 \mathrm{~h}$ recovery from $\mathrm{H} / \mathrm{I}$ were processed for TUNEL, visualized with Nova Red HRP substrate and counterstained briefly in Mayer's hematoxylin. A Representative medial region of the contralateral SVZ. B Representative medial region of the ipsilateral SVZ. C Representative mediolateral region of the contralateral SVZ. D Representative mediolateral region of the ipsilateral SVZ. E Representative lateral tail of the contralateral SVZ. F Representative lateral tail of the ipsilateral SVZ. Asterisks mark the location of the lateral ventricle; arrows mark TUNEL+ cells. Scale bar $=20 \mu \mathrm{m}$. 

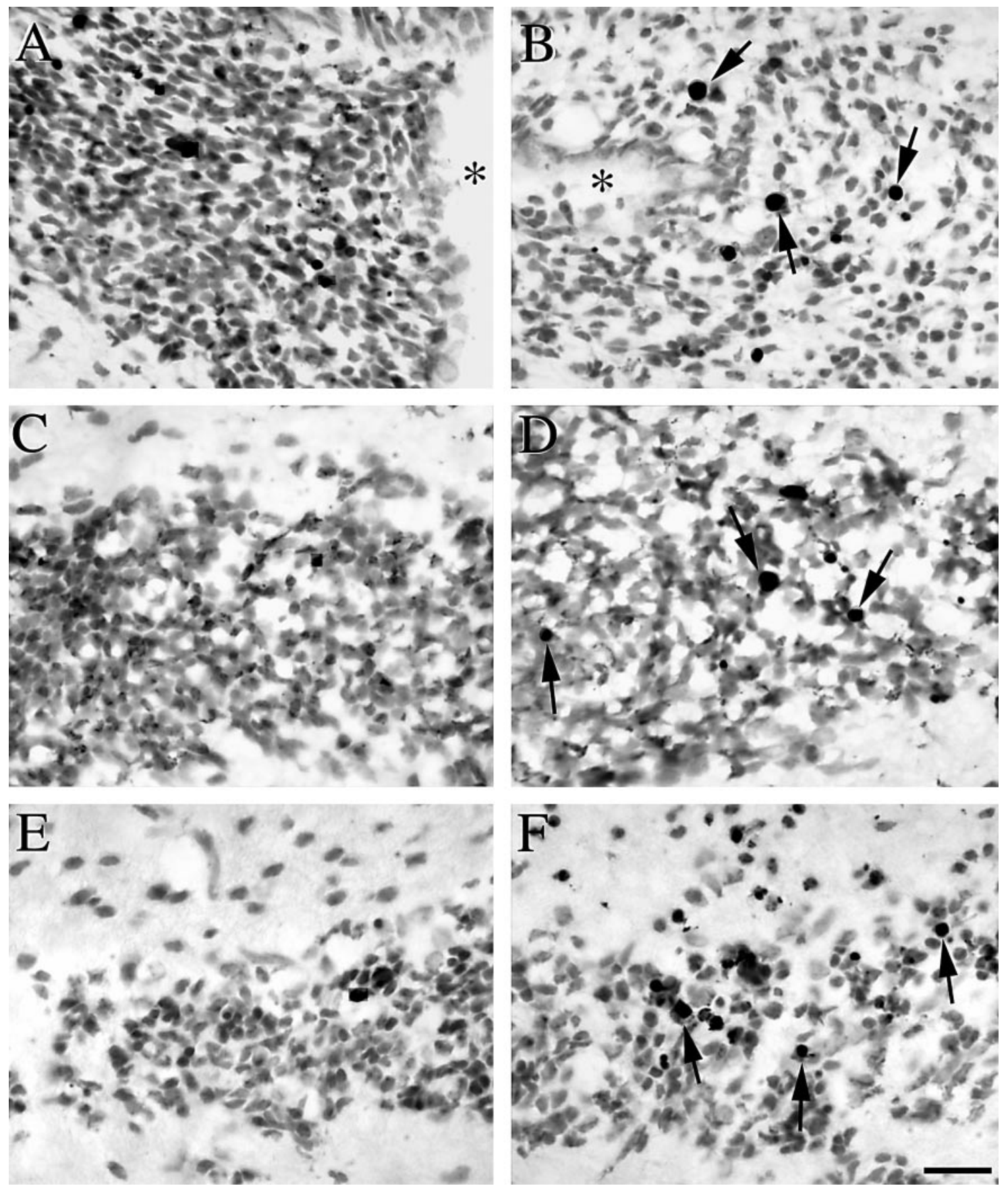

Fig. 3. TUNEL+ cells are increased in the $P 10$ mouse $S V Z$ at $18 \mathrm{~h}$ recovery. Cryostat sections taken at the level of the anterior commissure from P10 mouse brain at $18 \mathrm{~h}$ recovery from H/I were processed for TUNEL, visualized with Nova Red HRP substrate and counterstained briefly in Mayer's hematoxylin. A Representative medial region of the contralateral SVZ. B Representative medial region of the ipsilateral SVZ. C Representative mediolateral region of the contralateral SVZ. D Representative mediolateral region of the ipsilateral SVZ. E Representative lateral tail of the contralateral SVZ. F Representative lateral tail of the ipsilateral SVZ. Asterisks mark the location of the lateral ventricle; arrows mark TUNEL+ cells. Scale bar $=20 \mu \mathrm{m}$. 


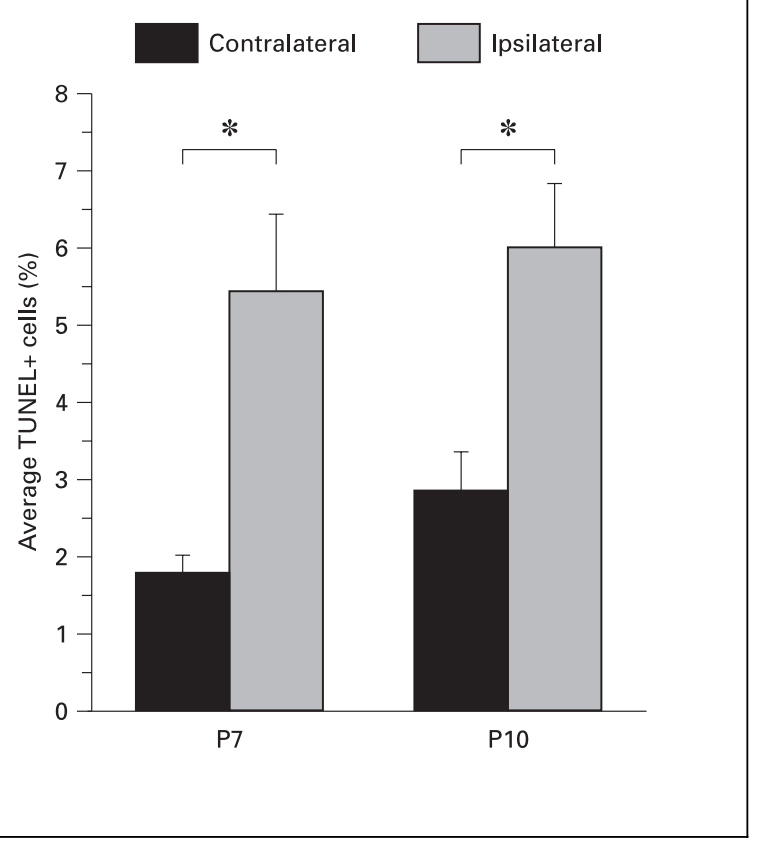

Fig. 4. $\mathrm{H} / \mathrm{I}$ increases TUNEL+ cells in both $\mathrm{P} 7$ and $\mathrm{P} 10$ mouse SVZ. Cryostat sections taken at the level of the anterior commissure from $\mathrm{P} 7$ and P10 mouse brain at $18 \mathrm{~h}$ recovery from $\mathrm{H} / \mathrm{I}$ were processed for TUNEL, visualized with Nova Red HRP substrate and counterstained briefly in Mayer's hematoxylin. The percentage of TUNEL+ cells present in the SVZ at $18 \mathrm{~h}$ following the insult was quantified. The number of TUNEL + cells was counted at $\times 60$ under oil immersion from 2 nonadjacent sections per brain. Data are presented as the percent TUNEL+ cells with respect to the total number of cells present in the dorsolateral SVZ. ${ }^{*} \mathrm{p}<0.02$ by Student's t test.

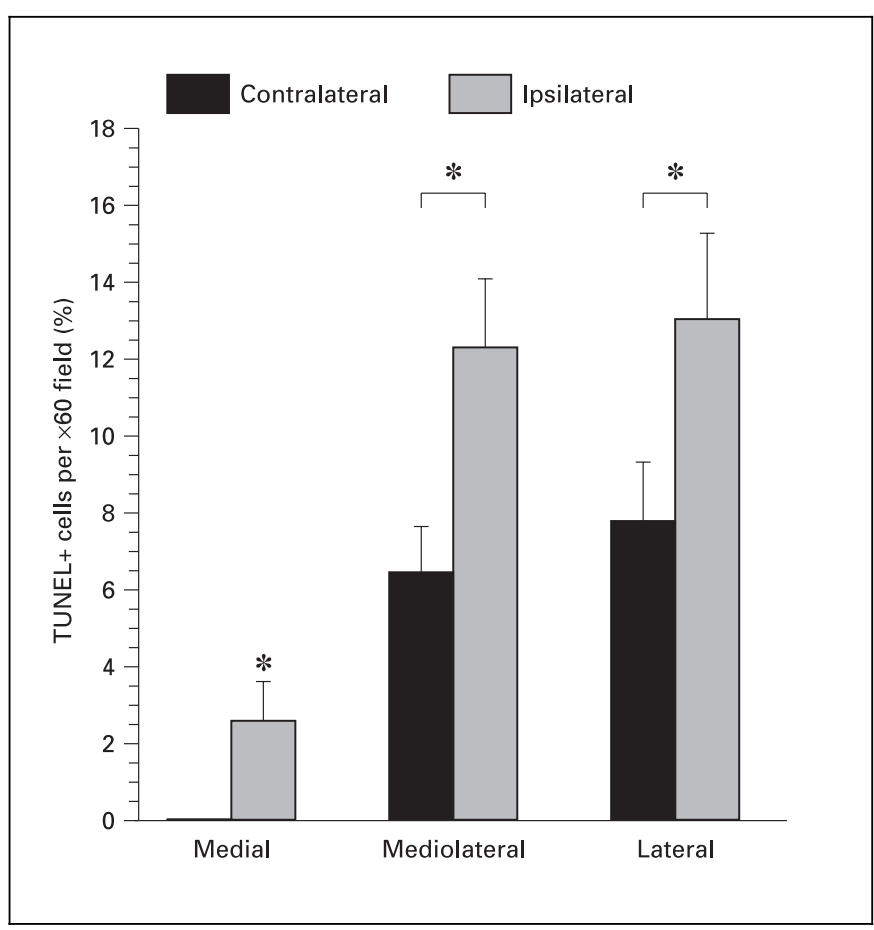

Fig. 5. H/I increases TUNEL+ cells in the mediolateral region and the lateral tail of the SVZ. Cryostat sections taken at the level of the anterior commissure from P10 mouse brain at $18 \mathrm{~h}$ recovery from H/I were processed for TUNEL, visualized with Nova Red HRP substrate and counterstained briefly in Mayer's hematoxylin. The percentage of TUNEL+ cells present in the first two cell layers of the ipsilateral SVZ (medial SVZ), the mediolateral SVZ (10-200 $\mu \mathrm{m}$ from the lateral ventricle) and the lateral SVZ (>200 $\mu \mathrm{m}$ from the lateral ventricle) were quantified and compared to the percentage of TUNEL+ cells present in the corresponding contralateral region of the SVZ. $* p<0.05$ by Student's t test.
Fig. 6. Active-caspase- $3+$ cells are increased in the ipsilateral P10 SVZ $18 \mathrm{~h}$ following $\mathrm{H} / \mathrm{I}$. Cryostat sections from P10 mouse brain were processed for the immunohistochemical detection of active caspase 3. A The ipsilateral SVZ contains a higher percentage of caspase-3+ cells as compared to the contralateral SVZ. ${ }^{*} \mathrm{p}<0.0005$. B Percentages of caspase-3+ cells in the first two cell layers of the SVZ (medial), mediolateral region (10$200 \mu \mathrm{m}$ from the lateral ventricle) and lateral region ( $>200 \mu \mathrm{m}$ from the lateral ventricle). $* \mathrm{p}<0.002$ by Student's $t$ test.

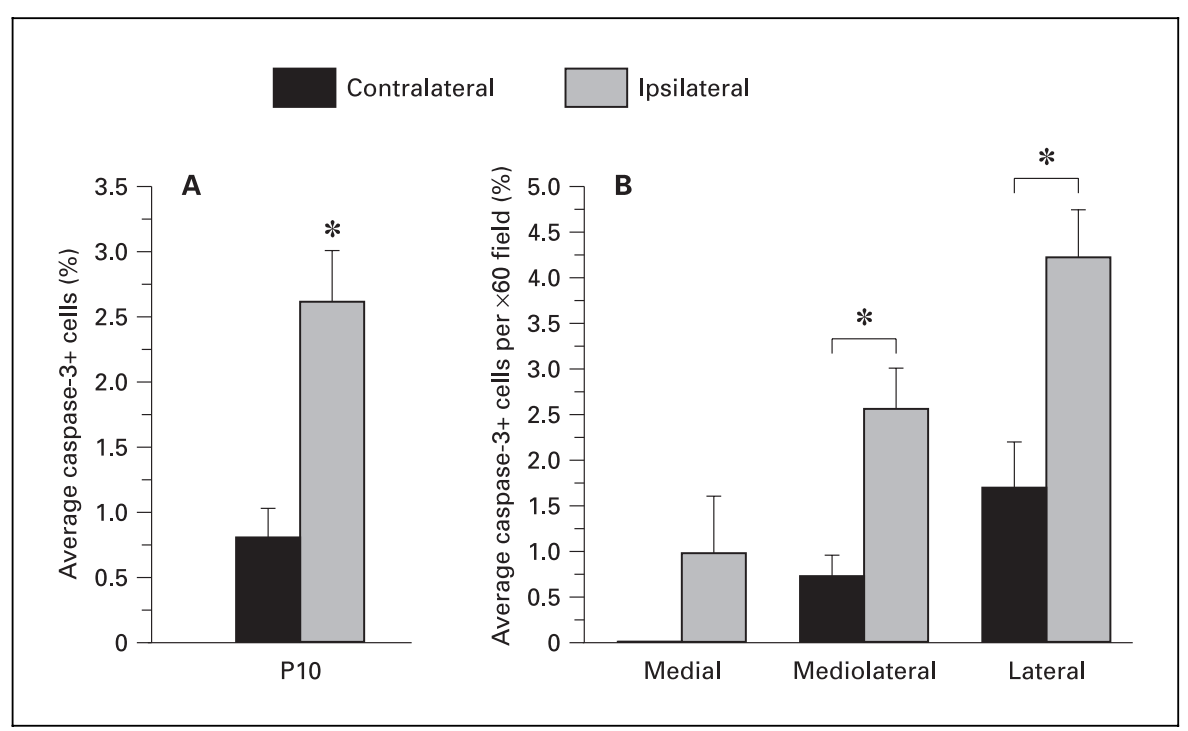

Brazel/Rosti/Boyce/Rothstein/Levison 


\section{Caspase 3 Is Activated in the SVZ of the P10 Mouse} $18 \mathrm{~h}$ following $H / I$

To determine whether caspase 3 is a death effector in the mouse SVZ following H/I, we processed cryostat sections for active caspase 3 immunoreactivity $18 \mathrm{~h}$ following the injury, followed by a brief counterstain with hematoxylin to label cell nuclei. Active-caspase-3+ cells were sparse in the mediolateral aspect of the contralateral SVZ. By contrast, cells with active caspase 3 were readily seen in the mediolateral aspect of the ipsilateral SVZ. Quantitation of caspase3 -immunoreactive cells revealed a 3.3-fold increase in caspase-3+ cells in the ipsilateral SVZ as compared to the contralateral SVZ (fig. 6A, $\mathrm{p}<0.0005$ ). When the percentage of caspase-3+ cells was examined regionally within the SVZ, only the mediolateral and lateral regions of the ipsilateral SVZ showed increased immunoreactivity as compared to the contralateral SVZ (fig. 6B; 3.5-fold and 2.5-fold increases, respectively; $p<0.002$ ). While an occasional caspase-3+ cell was observed in the first two cell layers of the ipsilateral SVZ (medial region), such cells were highly variable and there was no statistically significant increase in their frequency as compared to their frequency in the contralateral SVZ ( $p=0.09$, fig. 6B).

\section{Discussion}

While the injury sustained by the perinatal rat SVZ as a consequence of $\mathrm{H} / \mathrm{I}$ is beginning to be understood [7-9], the data are scant for the effects of this insult on the SVZ of the immature mouse [12]. Here, we investigated the effect of $70 \mathrm{~min}$ of $10 \% \mathrm{O}_{2}$ on SVZ cells of P5, P7 and P10 mice, in order to compare and contrast the damage seen to SVZ cells in the P7 rat. We find that this insult did not visibly damage the P5 mouse SVZ by $18 \mathrm{~h}$ of recovery. However, by P7, the frequency of TUNEL+ cells in the mouse SVZ is increased indicating that the P7 mouse SVZ is vulnerable to H/I. Interestingly, there is no discernable loss in total cellularity in the SVZ at $18 \mathrm{~h}$ recovery. By contrast, H/I insult in the P10 mouse produces both a decrease in cellularity and an increase in TUNEL+ cells by $18 \mathrm{~h}$ recovery. Additionally, at least some of the cells dying $18 \mathrm{~h}$ following injury initiate apoptosis through caspase 3 activation.

Damage to the P10 Mouse SVZ following H/I Is

Similar to That Seen in the P7 Rat

We used the $\mathrm{P} 7$ rat model of $\mathrm{H} / \mathrm{I}$ as a basis for damage assessment to the P5, P7 and P10 mouse SVZ $18 \mathrm{~h}$ following $\mathrm{H} / \mathrm{I}$ in order to determine whether the mouse SVZ was vulnerable to $\mathrm{H} / \mathrm{I}$ and if so, at which age the damage was quantitatively similar to that sustained in the $\mathrm{P} 7$ rat. We focused on the 3 main characteristics of SVZ cell death following H/I in the P7 rat: (1) a loss in total SVZ cellularity $[7,8]$; (2) compartmentalization of cell death to the mediolateral and lateral regions of the SVZ [8], and (3) activation of caspase 3 in regions where death is prevalent [9].

In the P5 mouse, damage to the SVZ was rarely seen as assessed by hematoxylin and eosin staining; thus, we focused our efforts on P7 and P10 mice. At P7, TUNEL+ cells were increased 3-fold in the ipsilateral SVZ as compared to the contralateral SVZ. However, the total cellularity of the SVZ at this age was unaffected. There are at least 2 explanations for this result: (1) There is little necrotic cell death in the P7 mouse SVZ cells early following H/I, or (2) SVZ cells in the P7 mouse initiate apoptosis later following $\mathrm{H} / \mathrm{I}$ than in the P7 rat, thus cellularity has not been affected by $18 \mathrm{~h}$ following the insult. In either case, we conclude that cell death in the P7 mouse differs from that seen in the P7 rat and is not a suitable model of asphyxia in the term infant, but may rather more closely resemble the type of damage seen following preterm asphyxia.

By contrast, the injury sustained by the P10 mouse SVZ is similar to that seen in the P7 rat. Not only are TUNEL+ cells increased 2-fold by $18 \mathrm{~h}$ following H/I, but the total cellularity of the SVZ is decreased by $16 \%$. Swelling of the cells in the most medial aspect of the P10 mouse SVZ mimics the swelling seen in the P7 rat SVZ $4 \mathrm{~h}$ following recovery and columns of swollen cells formed in the medial region as we have observed in the $\mathrm{P} 7$ rat SVZ (fig. 1) [8]. Additionally, as in the P7 rat, caspase 3 is activated $18 \mathrm{~h}$ following the injury, implicating a role for caspase-3-mediated apoptosis in the SVZ of P10 mice.

\section{Ependymal Cells and Putative Neural Stem Cells in the Medial SVZ Resist Injury during Recovery from Perinatal $H / I$}

Interestingly, our studies continue to demonstrate that the medial region of the SVZ, which contains the putative neural stem cells, is resilient to damage. In a previous study, Romanko et al. [9] described the death of progenitor cells but not stem cells in the medial region of the SVZ following $\mathrm{H} / \mathrm{I}$ in the perinatal rat. In that study, progenitor cells positive for polysialylated neural cell adhesion molecule (PSA-NCAM) were shown to activate caspase 3 and undergo apoptosis following $\mathrm{H} / \mathrm{I}$, while cells positive for the putative stem cell marker nestin never activated caspase 3 nor showed signs of cell death following H/I. In the current study, cells within and immediately subjacent to the ependymal layer never exhibited signs of dying; stud- 
ies are ongoing to determine whether PSA-NCAM+ but not nestin+ cells express caspase 3 following $H / I$ in the mouse.

Other studies in the rat have shown that cells of the ependymal and subependymal layers are in a state of high oxidative/hypoxic stress as visualized by EF5 adduct immunostaining [13]. However, despite these indications that the cells in the medial SVZ are under considerable stress as a consequence of $\mathrm{H} / \mathrm{I}$, the ependymal cells and those cells immediately subjacent to them within the SVZ resist damage as shown here and previously [8]. At the light- and electron-microscopic levels, we had previously shown that ependymal cells and those SVZ cells immediately subjacent were rarely apoptotic or necrotic. Furthermore, as we show here, TUNEL and active caspase$3+$ cells are rare amongst these cells. The low number of dying cells within the medial SVZ suggests that these cells may be intrinsically resilient to death effectors. Observations that support this hypothesis are: (1) glycogen granules are found within ependymal and subependymal cells, which would serve as an energy substrate during H/I, thus enabling these cells to survive this insult [14]; (2) ependymal and subependymal cells greatly rely upon anaerobic respiration, which can render these cells resistant to H/I
$[15,16]$; (3) neural stem cells have higher levels of antiapoptotic Bcl- $\mathrm{X}_{\mathrm{L}}$ which would endow them with resistance to cell death stimuli [17]. Additionally, large blood vessels are prominent in the medial regions of the germinal matrix of the human as well as the rodent SVZ, affording rapid reperfusion during recovery [18]. The hypothesis that these cells are not as severely affected by the insult is less tenable since those cells situated in the most medial region of the SVZ become significantly swollen early after perinatal $\mathrm{H} / \mathrm{I}$, indicating that they are indeed affected by this insult [8].

We conclude that the putative neural stem cells within the neonatal mouse SVZ are resilient to damage whereas progenitors located within more lateral aspects of the neonatal mouse SVZ are vulnerable to $\mathrm{H} / \mathrm{I}$ insult as are those in the rat. Additionally, these data suggest that mouse SVZ cells undergo apoptotic cell death subsequent to a perinatal $\mathrm{H} / \mathrm{I}$ insult and that caspase 3 is a mediator of that cell death. Finally, these studies demonstrate that the P10 mouse SVZ sustains damage as a consequence of an $\mathrm{H} / \mathrm{I}$ insult that is comparable to that observed in the $\mathrm{P} 7$ rat SVZ, making the P10 mouse an appropriate model for asphyxia at term.

\section{References}

$\checkmark 1$ Vannucci RC, Connor JR, Mauger DT, Palmer C, Smith MB, Towfighi J, Vannucci SJ: Rat model of perinatal hypoxic-ischemic brain damage. J Neurosci Res 1999;55:158-163.

$\checkmark 2$ Ferriero DM, Holtzman DM, Black SM, Sheldon RA: Neonatal mice lacking neuronal nitric oxide synthase are less vulnerable to hypoxicischemic injury. Neurobiol Dis 1996;3:64-71.

-3 Ditelberg JS, Sheldon RA, Epstein CJ, Ferriero DM: Brain injury after perinatal hypoxia-ischemia is exacerbated in copper/zinc superoxide dismutase transgenic mice. Pediatr Res 1996. 39:204-208.

$\checkmark 4$ Sheldon RA, Hall JJ, Noble LJ, Ferriero DM: Delayed cell death in neonatal mouse hippocampus from hypoxia-ischemia is neither apoptotic nor necrotic. Neurosci Lett 2001; 304:165-168

$\checkmark 5$ Sheldon RA, Sedik C, Ferriero DM: Strainrelated brain injury in neonatal mice subjected to hypoxia-ischemia. Brain Res 1998;810:114 122.

-6 Liu XH, Kwon D, Schielke GP, Yang GY, Silverstein FS, Barks JD: Mice deficient in interleukin-1 converting enzyme are resistant to neonatal hypoxic-ischemic brain damage. J Cereb Blood Flow Metab 1999;19:1099-1108.
7 Levison SW, Rothstein RP, Romanko MJ, Snyder MJ, Meyers RL, Vannucci SJ: Hypoxia/ ischemia depletes the rat perinatal subventricular zone of oligodendrocyte progenitors and neural stem cells. Dev Neurosci 2001;23:234247.

$>8$ Rothstein RP, Levison SW: Damage to the choroid plexus, ependyma and subependyma as a consequence of perinatal hypoxia/ischemia. Dev Neurosci 2002;24:426-436.

9 Romanko MJ, Rothstein RP, Vannucci SJ, Meyers RL, Levison SW: Stem/progenitor cells in the rat subependymal zone are vulnerable to hypoxia/ischemia. Soc Neurosci Abstr 2000; 26:281-288.

10 Gavrieli Y, Sherman Y, Ben-Sasson SA: Identification of programmed cell death in situ via specific labeling of nuclear DNA fragmentation. J Cell Biol 1992;119:493-501.

11 Gundersen HJ, Bendtsen TF, Korbo L, Marcussen N, Moller A, Nielsen K, Nyengaard JR, Pakkenberg B, Sorensen FB, Vesterby A, et al: Some new, simple and efficient stereological methods and their use in pathological research and diagnosis. APMIS 1988;96:379-394.

12 Skoff RP, Bessert DA, Barks JD, Song D, Cerghet M, Silverstein FS: Hypoxic-ischemic injury results in acute disruption of myelin gene expression and death of oligodendroglial precursors in neonatal mice. Int $\mathrm{J}$ Dev Neurosci 2001;19:197-208.
3 Bergeron M, Evans SM, Sharp FR, Koch CJ, Lord EM, Ferriero DM: Detection of hypoxic cells with the 2-nitroimidazole, EF5, correlates with early redox changes in rat brain after perinatal hypoxia-ischemia. Neuroscience 1999; 89:1357-1366.

14 Blakemore WF: The ultrastructure of the subependymal plate in the rat. J Anat 1969;104: 423-433.

15 Shimizu N, Morikawa N, Ishi Y: Histochemical studies of succinic dehydrogenase and cytochrome oxidase of the rabbit brain, with special reference to the results in the paraventricular structures. J Comp Neurol 1957;108:1-21.

16 Cammermeyer J: The hypependymal microglia cell. Z Anat Entwicklungsgesch 1965;124:543561.

17 Brazel CY: Neural Stem Cells Are Resistant to Apoptosis; doctoral dissertation in cell and molecular biology, Hershey, Pennsylvania State University, p 186.

18 Towbin A: Brain Damage in the Newborn and Its Neurologic Sequels: Pathological and Clinical Correlation. Danvers, PRM Publishing Co, 1998. 